\title{
Retinal pigment epithelial step sign: optical coherence tomography clue for diagnosing retained subretinal perfluorocarbon liquid
}

\author{
Srikanta Kumar Padhy, ${ }^{1}$ Brijesh Takkar, ${ }^{2}$ Anup Kelgaonkar (D) ,' Suman Sahu (D) ${ }^{1}$
}

${ }^{1}$ Ophthalmology, LV Prasad Eye Institute Bhubaneswar Campus, Bhubaneswar, Odisha, India ${ }^{2}$ Ophthalmology, LV Prasad Eye Institute, Hyderabad, Telengana, India

\section{Correspondence to} Dr Srikanta Kumar Padhy; srikantkumar.padhy19@gmail. com

Accepted 24 September 2021

\section{DESCRIPTION}

Optical coherence tomographic (OCT) features of a retained subretinal perfluorocarbon liquid (PFCL) include an omega-shaped conformation of the cyst, acute angle between the retinal pigment epithelium (RPE) and the neurosensory retina, compressed overlying retinal layers and an RPE hyper-reflective band with hyper-reflective shadowing of the underlying choroid. ${ }^{1}$ Since submacular PFCL mandates urgent removal, hence its recognition and differentiation from mimickers are crucial. We present an OCT clue indicating presence of retained subretinal PFCL and discuss its utility herein.

Case 1 presents a 24-year-old man who underwent a 23-gauge vitrectomy followed by PFCL (perfluoro-n-octane) injection, endolaser gauge, fluid-air exchange (FAE) and silicone-oil endotamponade for a chronic macula off retinal detachment in his right eye. The PFCL bubble was successfully aspirated prior to FAE. At first weekly postoperative visit, fundus evaluation revealed an attached retina under the silicone oil along with three well-defined dome-shaped refractile subretinal bubbles/cavities, the larger one lying below the fovea. OCT scan passing through fovea showed a well-demarcated hyporeflective cystic space at the fovea with subtle underlying RPE and choroidal hyper-reflectivity. The RPE below the cyst was noted to be slightly elevated simulating a step with respect to the adjacent 'uninvolved' RPE (figure 1A).

Case 2 presents a 60 -year-old man with a history of vitrectomy with the use of PFCL (perfluoro-noctane) to repair retinal detachment performed elsewhere. He was found to have submacular bubbles or fluid at 1 month of postoperative review. OCT vertical scan passing through fovea showed a domeshaped hyporeflective cystic space at the fovea with underlying RPE and choroid hyper-reflectivity. As in case 1, the RPE below the PFCL bubble was noted to be slightly elevated and 'stepped up' with respect to the adjacent RPE (figure $1 \mathrm{~B}$ ).

In both these cases, the subretinal bubbles had the previously described features of PFCL bubbles, namely (a) hyper-reflective shadowing, (b) highly defined cystic lesions and (c) sharp angulation between the neural retina and the RPE, along with underlying tissue hyper-reflectivity. Additionally, we found these cases to have an 'RPE step'. We
Check for updates

(C) BMJ Publishing Group Limited 2021. No commercial re-use. See rights and permissions. Published by BMJ.

To cite: Padhy SK, Takkar B, Kelgaonkar $\mathrm{A}$, et al. BMJ

Case Rep 2021;14:e244464. doi:10.1136/bcr-2021-

244464

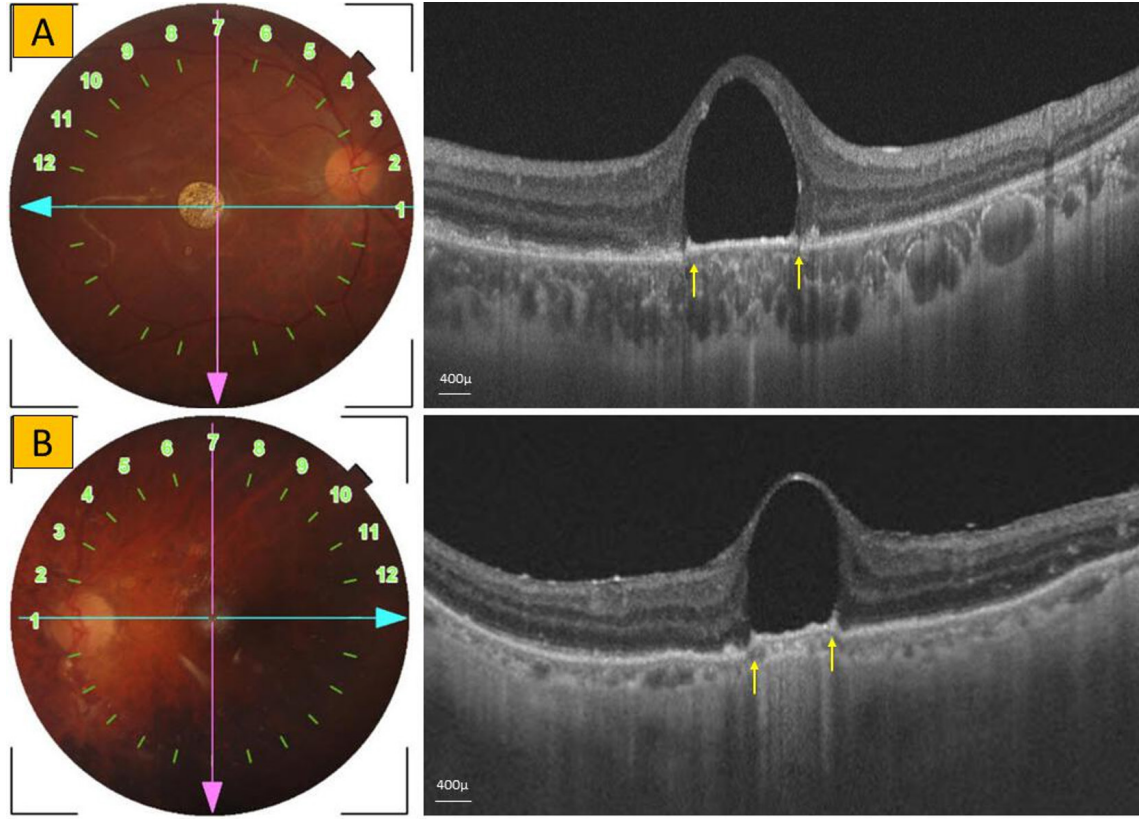

Figure 1 (A) Swept source optical coherence tomography vertical scan passing through fovea right eye shows a dome-shaped hyporeflective space at the fovea with subtle underlying retinal pigment epithelium (RPE) and choroid hyper-reflectivity with apparent RPE elevation (arrow, scale bar $400 \mu$ ). (B) Swept source optical coherence tomography vertical scan passing through fovea left eye shows a dome-shaped hyporeflective space at the fovea with subtle underlying RPE and choroid hyper-reflectivity with similar RPE elevation (arrow, scale bar $400 \mu$ ). 
propose that this apparent elevation of RPE is related to the refractive index of PFCL (1.27). The incident signal from the OCT (and reflected signal from sub-PFCL RPE) would experience refraction at the surface of PFCL bubble (Snell's law) giving us the illusion that sub-PFCL RPE is raised. ${ }^{1}$ It is noteworthy that refraction occurs only when the light is incident obliquely to the medium and not along a normal drawn to it. Strampe et al ${ }^{2}$ have reported image artefacts of handheld spectral domain OCT images of retained PFCL droplets on the surface of the retina ascribing to a lensing effect produced by the refractive index differences between the PFCL and vitreous humour. ${ }^{13}$ The clinical application of this sign is in recognising the nature of fluid trapped under the retina that cannot be assessed clinically, the most common being persistent loculated subretinal fluid (PSF) after small gauge vitrectomy for retinal detachment as reported by Mimouni et al. ${ }^{4}$ PSF can be observed while retained subretinal PFCL mandates surgical intervention. Another close mimicker is the presence of subretinal cysticercosis, which mimics subretinal PFCL clinically and also on many features on OCT, though there is no underlying RPE step. ${ }^{5}$ In author's belief, the reasons for absence of the illusionary step of the RPE are likely to stem from

\section{Patient's perspective}

I am happy that my disease could be diagnosed so as to avail of immediate further consult and treatment. I and my family members have been apprised about my condition, its natural course and possible complications. The need for regular follow up and self-awareness of visual loss has been explained to me in a language that I can easily understand.

\section{Learning points}

Apparent elevation of subretinal perfluorocarbon liquid (PFCL) retinal pigment epithelium (RPE) is related to the refractive index of PFCL.

- RPE step can be considered as an optical coherence tomographic marker to differentiate subretinal PFCL from persistent loculated subretinal fluid and subretinal cysticercosis. different refractive indices of the PSF and the cyst contents of cysticercosis as compared with PFCL.

Practically hypothesising, subretinal silicone oil globule of a larger size can also show RPE step on OCT. This does limit generalisation of our finding. However, if we compare the interfacial tension between the silicone oil and PFCL, the former has a lower value; which further decreases in the vitreous cavity in the presence of viscoelastic solutions, blood, proteins, lipids and ionised solutions (eg, biological fluids). Therefore, compared with more frequent larger coalesced bubble of PFCL, silicone oil tends to form multiple small bubbles with incomplete septum between them. This will make the RPE step sign less obvious on OCT. Another fact is that subretinal silicone oil typically will be an accompaniment of recurrent retinal detachment, open breaks and proliferative retinopathy; whereas PFCL, as in our cases, can be present with smoothly attached retina. In case of subretinal oil, presence of retinal detachment will make the step sign less apparent if macular area is involved. Considering these, and the rarity of subretinal silicone oil in attached retina, the step is more likely an indicator of PFCL.

Contributors SKP - conception of idea, manuscript writing and data collection. BT—manuscript writing and review. SS and AK—-manuscript review and data collection.

Funding This study was funded by Hyderabad Eye Research Foundation (LVPEIbcr-2021).

Competing interests None declared.

Patient consent for publication Obtained.

Provenance and peer review Not commissioned; externally peer reviewed.

\section{ORCID iDs}

Anup Kelgaonkar http://orcid.org/0000-0002-3983-4200

Suman Sahu http://orcid.org/0000-0002-9664-9554

\section{REFERENCES}

1 Sigler EJ, Randolph JC, Rafieetary MR, et al. Spectral domain optical coherence tomography characteristics of retained subretinal perfluoro-n-octane. Retin Cases Brief Rep 2013;7:164-8.

2 Strampe MR, Kaehr MM, Carroll J, et al. Intraoperative imaging of retained perfluorocarbon liquid using spectral domain optical coherence tomography. Retin Cases Brief Rep 2019;13:381-4.

3 Langlo CS, Flatter JA, Dubra A, et al. A lensing effect of inner retinal cysts on images of the photoreceptor mosaic. Retina 2014;34:421-2.

4 Mimouni M, Jaouni T, Ben-Yair M, et al. Persistent loculated subretinal fluid after rhegmatogenous retinal detachment surgery. Retina 2020;40:1153-9.

5 Sinha S, Takkar B, Venkatesh P, et al. High-Resolution Fourier-domain optical coherence tomography findings in subretinal cysticercosis. Retina 2012;32:643-4.

Copyright 2021 BMJ Publishing Group. All rights reserved. For permission to reuse any of this content visit

https://www.bmj.com/company/products-services/rights-and-licensing/permissions/

BMJ Case Report Fellows may re-use this article for personal use and teaching without any further permission.

Become a Fellow of BMJ Case Reports today and you can:

- Submit as many cases as you like

- Enjoy fast sympathetic peer review and rapid publication of accepted articles

- Access all the published articles

- Re-use any of the published material for personal use and teaching without further permission

Customer Service

If you have any further queries about your subscription, please contact our customer services team on +44 (0) 2071111105 or via email at support@bmj.com.

Visit casereports.bmj.com for more articles like this and to become a Fellow 